\title{
Electrophysiological Study on the Influence of the Morphine Microiontophoresis on Firing Activity of Neurons in Nuclei Related to Acupuncture Analgesia
}

\author{
Won Jong*, Myong Hui Kim
}

\section{Won Jong* Myong Hui Kim}

Research Unit of Electrophysiology, Pyongyang University of Medical Sciences, DPR of KOREA.

\section{*Correspondence}

\section{Dr. Won Jong}

Research Unit of Electrophysiology, Pyongyang University of Medical Sciences, DPR of KOREA.

Email: heavenlake_hana@ 126.com

\section{History}

- Submission Date: 07-04-2021;

- Review completed: 28-05-2021;

- Accepted Date: 12-06-2021.

DOI : 10.5530/ijcep.2021.8.2.16

\section{Article Available online}

http://www.ijcep.org

\section{Copyright}

(C) 2021 Phcog.Net. This is an openaccess article distributed under the terms of the Creative Commons Attribution 4.0 International license.

\begin{abstract}
Background and Aim: Many nuclei such as periaqueductal central gray (PAG), raphe magnus nucleus (RMG) and gigantocellular reticular nucleus (Gi) are related in acupuncture analgesia. The aim of this study is to find the analgesic characteristics when dorsolateral periaqueductal gray (DLPAG), ventrolateral periaqueductal gray (VLPAG), RMG and Gi were individually stimulated in rat. Methods: Wistar rats (200 230g) were used in experiments. Rats were put in a small plastic box except the tail when the tail of a rat was stimulated by using radiant heat, tail flick latency (TFL), threshold of the painful response on account of the radiant heat was determined. The stimulus experiments were performed 3 to 5 days after inserting the electrodes. The current intensity for microiontophoresis is 30nA and time is 20s. Results: When DLPAG was locally stimulated in rats, the analgesia gradually appeared. Its characteristics resembled those of electroacupuncture at ST36 point. And then the analgesic effect appeared only in the period when VLPAG, RMG and Gi were individually stimulated in rats, but didn't appear after cessation of stimulation. The rates of the excited neurons in the VLPAG, RMG and Gi were increased by microiontophoresis of morphine. Conclusion: There are mechanisms inhibiting the painful impulse in input of spinal cord by influence of endogenous morphine-type substance affecting neurons in VLPAG, RMG, and $\mathrm{Gi}$ among the mechanisms of electroacupuncture analgesia on ST36 point.

Key words: Acupuncture, Analgesia, Electroacupuncture, Electrophysiology, Microiontophoresis.
\end{abstract}

\section{INTRODUCTION}

Acupuncture plays an important role in traditional medicine especially electroacupuncture is used widely in clinical practice. The most important effect of acupuncture is analgesia. Many nuclei such as periaqueductal central gray (PAG), raphe magnus nucleus (RMG) and gigantocellular reticular nucleus (Gi) are concerned in acupuncture analgesia.

The electroacupuncture changed the impulse activity of neurons in PAG and raphe nuclei, the analgesia by electroacupuncture disappeared if PAG, raphe nuclei were destroyed or when naloxone, the antagonist of morphine was injected in the animal. ${ }^{[1,2]}$ When RMG was locally stimulated in rats, firing activity of neurons in posterior horn of spinal cord was depressed. ${ }^{[3]}$ Electroacupuncture analgesia lasted for a while after cessation of electroacupuncture. If hypophysis which secretes the endorphin was destroyed, the analgesia by acupuncture disappeared. ${ }^{[4]}$ This effect was observed whenever naloxone was injected in brain. ${ }^{[5]}$ And the endorphin and encephalin in cerebrospinal fluid (CSF) were increased by acupuncture. ${ }^{[6-8]}$

There are a lot of morphine-type substances in brain extract of rats which could cause analgesia by acupuncture. ${ }^{[9,10]}$ This showed that the role of humoral factors especially morphine-type substances are very important in acupuncture analgesia.

As a result, a lot of the experiments on microinjection of morphine were carried out with experiments for stimulation and destruction of nucleus in the brain. The obvious analgesia of morphine appeared, when the morphine was microinjected into magnocellular nucleus, PAG and lateral reticular nucleus of midbrain. ${ }^{[11-13]}$ And neurons with different characteristics exist there. Microinjection of morphine on the thalamus inhibited effectively the reaction of neurons in posterior horn of spinal cord by formalin nociceptive stimulus. And the effect was significantly decreased by microinjection of naloxone $(1,0.5 \mu \mathrm{g})$, antagonist of opioid receptor. [14] Researches mentioned above showed that the blockage of painful impulse in input of spinal cord by influence of nuclei in brain and endogenous morphine-type substances are important in acupuncture analgesia.

Cite this article: Jong W, Kim MH. Electrophysiological Study on the Influence of the Morphine Microiontophoresis on Firing Activity of Neurons in Nuclei Related to Acupuncture Analgesia. Int J Clin Exp Physiol. 2021;8(2):65-9. 
In this study, we introduced the analgesia characteristics when PAG, RMG and Gi were individually stimulated in rats, and the reactive characteristics of neurons in VLPAG, RMG and Gi by microiontophoresis of morphine to them.

\section{MATERIALS AND METHODS}

\section{Animals}

Adult male Wistar rats weighing 200-230 g were included in the study. All the rats were allowed for free access to food and water before surgery under optimal conditions ( $12 / 12 \mathrm{~h}$ light/dark with humidity $60 \pm 5 \%$, $22 \pm 3^{\circ} \mathrm{C}$ ). All animals were taken care as recommended in the Guide for the Care and Use of Laboratory Animals issued by the D.P.R. of $\mathrm{K}$ Association of Laboratory Animal Care.

\section{Determination of TFL by Radiant Heat in a Rat}

Rats were put in a small plastic box except the tail. The tail of rats were stimulated by using radiant heat and TFL, threshold of the painful response on account of the radiant heat was determined. ${ }^{[13]}$

\section{Local Stimulus and Destruction of the Some Brain Structures in a Rat}

Rats were induced anesthesia by injecting thiopental at a dose of $60 \mathrm{mg}$ / $\mathrm{kg}$ and they were fixed on the stereotaxic apparatus, and then electrodes were inserted into the brain of the rats according to the stereotaxic atlas of rat brain (Paxinos and Watson, 1997). After that, the electrodes were fixed on the bones of skull by using acrylic resins. ${ }^{[15]}$ The stimulus experiments were performed 3 to 5 days after inserting the electrodes. By using the current stimulator (ELECTROSTIMULATOR ST-3, Hungary), the brain nucleus was stimulated with continuous impulse $(0.1 \sim 0.2 \mathrm{~mA}$, $0.2 \mathrm{~ms}, 50 \mathrm{~Hz}$ ). Stimulation sites were marked by passing DC current ( 0.6 to $0.9 \mathrm{~mA}, 30 \mathrm{~s}$ ) through this electrode. In some experiments, brain nuclei of rats were destroyed by passing the current ( $1 \mathrm{~mA}, 40 \mathrm{~s})$.

At the completion of each experiment, the animals were perfused with normal saline. The brain was then removed, stored in $10 \%$ formaldehyde for 3 days, and sectioned on a microtome to locate stimulation sites. The stimulation sites located outside the bounds of the DLPAG, VLPAG, GI, and RMG were not included in the results.

\section{Microiontophoresis}

Three-barrelled glass micropipettes were used for experiment. The current intensity for microiontophoresis is $30 \mathrm{nA}$ and time is $20 \mathrm{~s}$. The sites of tip of electrode were verified by methylene blue (MB) labeling. ${ }^{[16]}$ The current of 50nA passed through electrode with methylene blue for 100s. The quantity of electricity that passed through electrode was 5000nC. All microiontophoretic manipulations were performed using the Neurophore BH-2 units (Medical Systems Cor.). At the end of each recording session, animals were perfused with normal saline solution followed by $4 \%$ paraformaldehyde. Brains were post-fixed in $4 \%$ paraformaldehyde for one day. After post-fixation, slices were cut on a sliding microtome for examination of the ejection sites. Sections were studied under a light microscope (Olympus $\mathrm{BH} 2$ ).

\section{Statistical Analysis of Data}

All data were expressed as mean \pm SD. Inter-group differences were compared by two-tailed independent sample $t$ test using SPSS 10.0 statistical software. Differences were considered statistically significant at a probability level equal to or less than 0.05 .

\section{RESULTS AND DISCUSSION}

\section{Influence of Electroacupuncture of Zusanli Point (ST36)} on the Tail Flick Latency (TFL)

The influence of electroacupuncture at ST36 on TFL by radiant heat in rats was observed. We divided the rats into two groups i.e. effective and ineffective group on acupuncture, analgesia effect in effective group was 1.2 times higher than control. We did the experiment in the effective group. When a rat was stimulated by electroacupuncture (1 2Hz, 20min, KWD-8081, China) at the ST36point, TFL changed as follows (Table1). As shown in the Table 1, when a rat was stimulated by electroacupunncture (1 2Hz, 20min, KWD-8081, China) at Zusanlii point (ST36) of a rat, the analgesia gradually appeared in the rat. And the analgesia effect was the highest $30 \mathrm{~min}$ after acupuncture, the effect of analgesia persisted for a while after stop of electroacupuncture.

\section{Influence of PAG on Acupuncture Analgesia on ST36 point in Effective Group of Rats in Acupuncture Analgesia}

Influence of PAG on acupuncture analgesia on ST36 was observed in effective group in acupuncture analgesia. First of all, the changes of TFL of a rat on radiant heat were observed in the effective group in acupuncture analgesia, when a Dorsolateral periaqueductal gray (DLPAG) was locally stimulated in rats (Figure 1, Table 2). When DLPAG was locally stimulated in rat, the analgesic effect gradually appeared, the characteristic of which was similar to that of ST36 point acupuncture. This shows DLPAG is associated with analgesia by acupuncture on ST36 point.

In fact, when ST36 point was stimulated after destruction of DLPAG, the analgesia didn't appear (Table 3). The characteristics that result in some latency and persistence in the analgesia by ST36 point acupuncture shows that the analgesia by acupuncture is related to humoral mechanism. But the TFL was elongated by local stimulus of VLPAG (Ventrolateral

Table 1: Changes of TFL by acupuncture in rat.

\begin{tabular}{ccccccccc} 
Items & $\begin{array}{c}\text { Before } \\
\text { Stimulus } \\
\text { (control) }\end{array}$ & 5 & 10 & 20 & 30 & 40 & 50 & 60 \\
TFL(s) & $2.56 \pm 0.47$ & $2.72 \pm 0.47$ & $3.17^{*} \pm 0.20$ & $3.77^{* *} \pm 0.48$ & $4.63^{* *} \pm 0.34$ & $4.06^{* *} \pm 0.34$ & $3.56^{* *} \pm 0.56$ & $3.27^{*} \pm 0.59$ \\
$\begin{array}{c}\text { Elongation } \\
\text { rate } \\
\text { of TFL(\%) }\end{array}$ & 100.0 & 106.3 & 123.8 & 147.3 & 180.8 & 158.6 & 139.1 & 127.7 \\
\hline
\end{tabular}

Values were expressed as mean $\pm \mathrm{SD}(\mathrm{n}=7) .{ }^{*} \mathrm{P}<0.05$ was considered as statistically significant.

${ }^{*} \mathrm{P}<0.05$ versus control; ${ }^{* *} \mathrm{P}<0.01$ versus before stimulus 
periaqueductal gray) only when it was excited (Table 4). As shown in the Table 4, when VLPAG was stimulated in a rat, TFL was elongated in the period of stimulating the VLPAG (192.9\%). i.e. the analgesic effect appeared only in the period when VLPAG was stimulated, but didn't appear after cessation of stimulation.

In the experiment, the bipolar electrodes were used to stimulate or destroy the DLPAG and VLPAG. The electrode tip sites for the electrical stimulation and the electrical destroy were marked with electrolytic lesion to histologically verify their locations in these structures.

\section{Influence of RMg and Gi to TFL of a Rat on Radiant Heat}

Characters of analgesia observed by local stimulus to VLPAG also appeared in RMg and Gi. As shown in the Table 5, when RMg and Gi were individually simulated in a rat (Figure 2), TFL were elongated $151.3,154.5 \%$ respectively. But the elongation of TFL did not appear after stimulus. That is, there was not any analgesic effect after cessation of stimulus.

When above data of Tables 4, 5 were analyzed with characteristics of ST36 point acupuncture analgesia, it showed that VLPAG, RMG, Gi turn into sites affected by endogenic opioid substance to be concerned in the acupuncture analgesia. So, we studied the change of impulse activity of neurons in VLPG, RMG, Gi of a rat by microiontophoresis of morphine.
Influence of Morphine Microiontophoresis on Impulse Activity of Neurons in VLPAG, RMG and Gi

First, the changes of impulse activity of neurons in VLPAG on morphine microiontophoresis were studied. There were many neurons discharging spontaneously impulse in VLPAG (Figure 3). They were divided into excited neurons, inhibited neurons and changeless neurons according to discharging frequency, and the changes of impulse activity of neurons by microiontophoresis were analyzed.

As shown in the Table 6, the rate of excited neurons was increased from $23.3 \%$ to $58.2 \%$ and the rate of changeless neurons was decreased from $43.3 \%$ to $18.3 \%$ when microiontophoresis of morphine was performed in VLPAG. And then, the changes of impulse activity of neurons by microiontophoresis of morphine in RMg, Gi were studied. As shown in the Table 7, the rate of excited neurons by microiontophoresis was increased than control in $\mathrm{RMg}(53.8 \%)$, and rate of excited neurons by microiontophoresis was increased than control in Gi (49.6\%) (Figure 4).

These show that the endogenous morphine-type substances are released by acupuncture and these can activate the neurons in VLPAG, RMg, Gi. As a result, the characteristic latency and the aftereffect are related with such mechanism. These are in accordance with results of experiment for local stimulus of VLPAG, RMg and Gi respectively.

Table 2: Changes of TFL of rat, when exciting DLPAG.

\begin{tabular}{|c|c|c|c|c|c|c|c|c|}
\hline \multirow{2}{*}{ Items } & \multirow{2}{*}{$\begin{array}{l}\text { Before } \\
\text { Stimulus } \\
\text { (control) }\end{array}$} & \multicolumn{7}{|c|}{ After stimulus (min) } \\
\hline & & 5 & 10 & 20 & 30 & 40 & 50 & 60 \\
\hline TFL(s) & $2.00 \pm 0.37$ & $2.30 \pm 0.23$ & $2.46^{*} \pm 0.19$ & $2.94^{* *} \pm 0.18$ & $3.14^{* *} \pm 0.36$ & $2.95^{\star *} \pm 0.33$ & $3.09^{*} \pm 0.26$ & $2.74^{*} \pm 0.10$ \\
\hline $\begin{array}{c}\text { Elongation } \\
\text { rate of } \\
\text { TFL (\%) }\end{array}$ & 100.0 & 115.0 & 123.0 & 147.0 & 157.0 & 147.5 & 152.5 & 137.0 \\
\hline
\end{tabular}

Values were expressed as mean $\pm \mathrm{SD}(\mathrm{n}=7) .{ }^{*} \mathrm{P}<0.05$ was considered as statistically significant.

${ }^{*} \mathrm{P}<0.05,{ }^{* *} \mathrm{P}<0.01$ versus before stimulus

Table 3: Changes of TFL of rat by ST36 point acupuncture after destroying DLPAG.

\begin{tabular}{ccccccccc} 
Items & $\begin{array}{c}\text { Before } \\
\text { stimulus }\end{array}$ & $\mathbf{5}$ & 10 & 20 & 30 & 40 & 50 & 60 \\
\hline TFL(s) & $1.96 \pm 0.09$ & $2.03 \pm 0.54$ & $2.06 \pm 0.67$ & $2.06 \pm 0.67$ & $2.08 \pm 0.06$ & $2.09 \pm 0.14$ & $1.69 \pm 0.09$ & $2.06 \pm 0.12$ \\
$\begin{array}{c}\text { Elongation rate } \\
\text { of TFL (\%) }\end{array}$ & 100.0 & 103.6 & 105.1 & 105.1 & 106.6 & 106.6 & 100.0 & 105.1 \\
\hline
\end{tabular}

Table 4: Changes of TFL of rat by local stimulus of VLPAG.

\begin{tabular}{|c|c|c|c|c|c|c|c|c|}
\hline \multirow{2}{*}{ Items } & \multirow{2}{*}{$\begin{array}{l}\text { Before } \\
\text { stimulus } \\
\text { (control) }\end{array}$} & \multicolumn{7}{|c|}{ After stimulus (min) } \\
\hline & & 5 & 10 & 20 & 30 & 40 & 50 & 60 \\
\hline TFL(s) & $1.98 \pm 0.19$ & $3.82^{*} \pm 0.55$ & $2.27 \pm 0.37$ & $2.06 \pm 0.09$ & $2.00 \pm 0.15$ & $2.01 \pm 0.19$ & $1.99 \pm 0.22$ & $2.07 \pm 0.15$ \\
\hline $\begin{array}{c}\text { Elongation rate } \\
\text { of TFL(\%) }\end{array}$ & 100.0 & 192.9 & 114.6 & 104.0 & 100.0 & 101.5 & 100.5 & 104.5 \\
\hline
\end{tabular}

Values were expressed as mean \pm SD $(n=7)$.

${ }^{\star} \mathrm{P}<0.05$ was considered as statistically significant. ${ }^{*} \mathrm{P}<0.05$ versus before stimulus 
Table 5: Influence of RMg and Gi stimulus to TFL of rat.

\begin{tabular}{|c|c|c|c|c|c|c|c|c|c|}
\hline \multirow{2}{*}{ Nucleuses } & \multirow{2}{*}{ Items } & \multirow{2}{*}{$\begin{array}{c}\text { Before } \\
\text { Stimulus(Control) }\end{array}$} & \multicolumn{7}{|c|}{ After stimulus ( $\mathrm{min}$ ) } \\
\hline & & & 5 & 10 & 20 & 30 & 40 & 50 & 60 \\
\hline \multirow{3}{*}{$\mathrm{RMg}$} & \multirow{2}{*}{ TFL(s) } & $1.99 \pm$ & $3.01^{*} \pm$ & $2.21 \pm$ & $2.06 \pm$ & $2.02 \pm$ & $2.01 \pm$ & $1.98 \pm$ & $2.07 \pm$ \\
\hline & & 0.17 & 0.5 & 0.36 & 0.09 & 0.14 & 0.19 & 0.17 & 0.15 \\
\hline & $\begin{array}{c}\text { Elongation rate } \\
\text { of TFL (\%) }\end{array}$ & 100.0 & 111.1 & 103.5 & 101.5 & 101.5 & 101.0 & 99.5 & 104.5 \\
\hline \multirow{3}{*}{$\mathrm{Gi}$} & \multirow{2}{*}{ TFL(s) } & $2.55 \pm$ & $3.94^{\star} \pm$ & $2.43 \pm$ & $2.55 \pm$ & $2.55 \pm$ & $2.49 \pm$ & $2.52 \pm$ & $2.72 \pm$ \\
\hline & & 0.14 & 0.6 & 0.12 & 0.18 & 0.14 & 0.10 & 0.13 & 0.31 \\
\hline & $\begin{array}{c}\text { Elongation rate } \\
\text { of TFL (\%) }\end{array}$ & 100.0 & 154.5 & 95.5 & 100.0 & 100.0 & 97.6 & 98.8 & 106.6 \\
\hline
\end{tabular}

Values were expressed as mean $\pm \mathrm{SD}(\mathrm{n}=7)$.

${ }^{\star} \mathrm{P}<0.05$ was considered as statistically significant. ${ }^{*} \mathrm{P}<0.05$ versus before stimulus

Table 6: Reactionary rates of neurons in the VLPAG by microiontophoresis of morphine.

\begin{tabular}{ccccc} 
Groups & Number of neurons & Rate of excited neurons (\%) & Rate of inhibited neurons (\%) & $\begin{array}{c}\text { Rate of changeless } \\
\text { neurons (\%) }\end{array}$ \\
\hline Control & $28(100.0 \%)$ & 23.3 & 33.4 & 43.3 \\
Experiment & $26(100.0 \%)$ & $58.2^{*}$ & 25.5 & $18.3^{*}$
\end{tabular}

${ }^{\star} \mathrm{P}<0.05$ was considered as statistically significant. ${ }^{*} \mathrm{P}<0.05$ versus control group

Table 7: Reactionary rates of neurons in the RMG and Gi by the microiontophoresis.

\begin{tabular}{cccccc} 
Nucleuses & Groups & Number of neurons & $\begin{array}{c}\text { Rate of excited } \\
\text { neurons(\%) }\end{array}$ & $\begin{array}{c}\text { Rate of inhibited } \\
\text { neurons(\%) }\end{array}$ & $\begin{array}{c}\text { Rate of changeless } \\
\text { neurons(\%) }\end{array}$ \\
\multirow{2}{*}{$\mathrm{RMg}$} & Control & $28(100.0 \%)$ & 21.5 & 28.7 & 49.8 \\
& Experiment & $26(100.0 \%)$ & $53.8^{*}$ & 23.1 & $23.1^{*}$ \\
\multirow{2}{*}{$\mathrm{Gi}$} & Control & $30(100.0 \%)$ & 19.8 & 27.4 & 52.8 \\
& Experiment & $28(100.0 \%)$ & $49.6^{*}$ & 25.2 & $25.2^{*}$
\end{tabular}

${ }^{*} \mathrm{P}<0.05$ was considered as statistically significant. ${ }^{*} \mathrm{P}<0.05$ versus control group

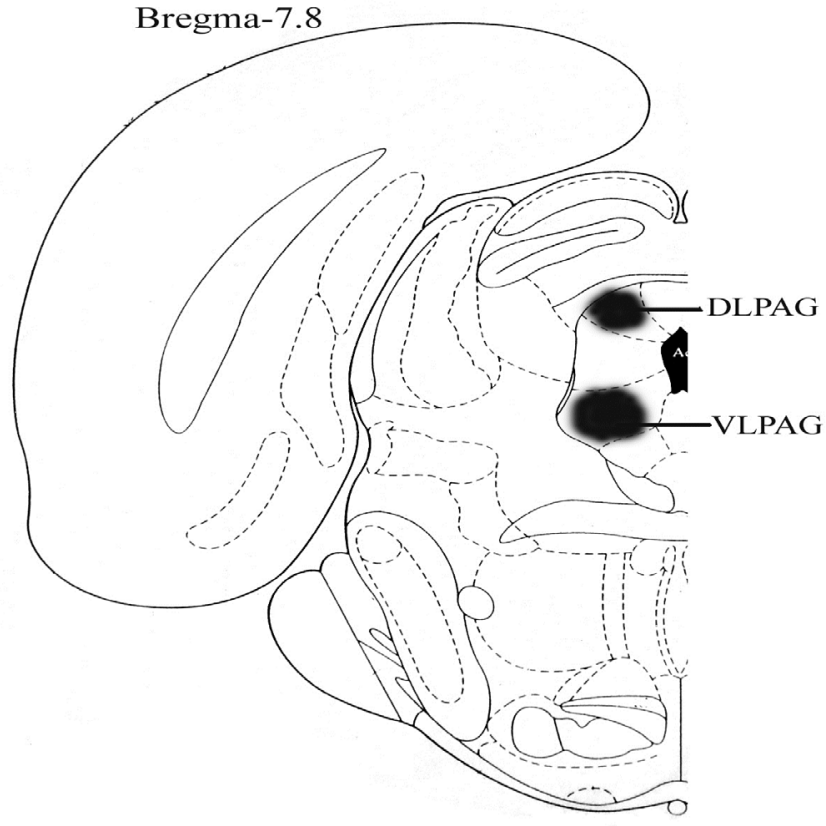

Figure 1: Diagramatic coronal section of the DLPAG and VLPAG indicating the locations of the electrical stimulation and destroy sites within rat brain. DLPAC: Dorsolateral periaqueductal gray; VLPAG: Ventrolateral periaqueductal gray.

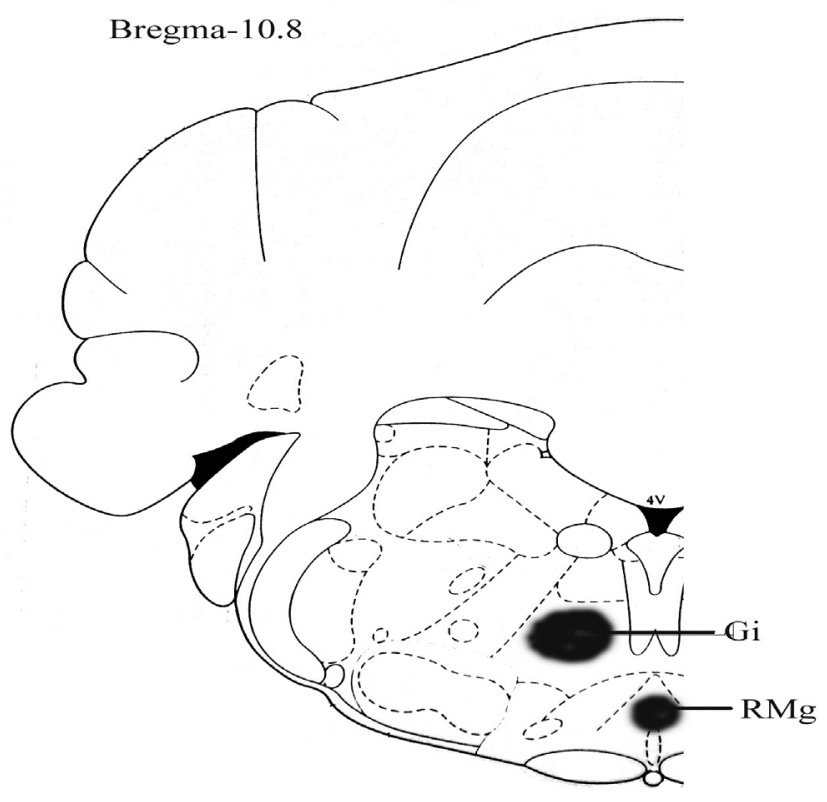

Figure 2: Diagramatic coronal section of the Gi and RMg indicating the locations of the electrical stimulation site in rat brain.

Gi: Gigantocellular reticular nucleus; RMg: Raphe magnus nucleus. 


\section{Bregma-7.80}

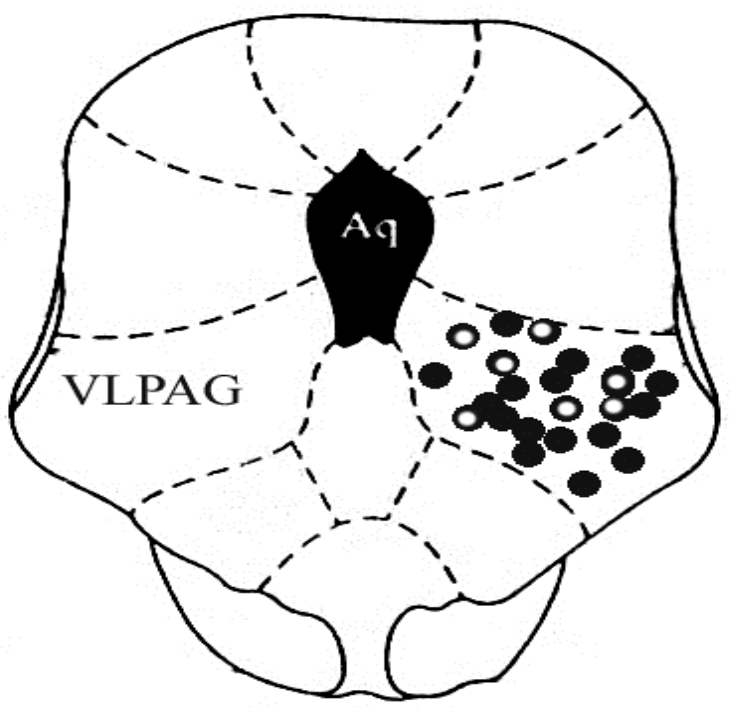

Figure 3: Diagramatic coronal section of the rat VLPAG indicating the location of the microiontophoresis electrode tip.

Aq: Aqueduct (Sylvius); VLPAG: Ventrolateral periaqueductal gray. Filled circles: Excited; Unfilled circles: Inhibited.

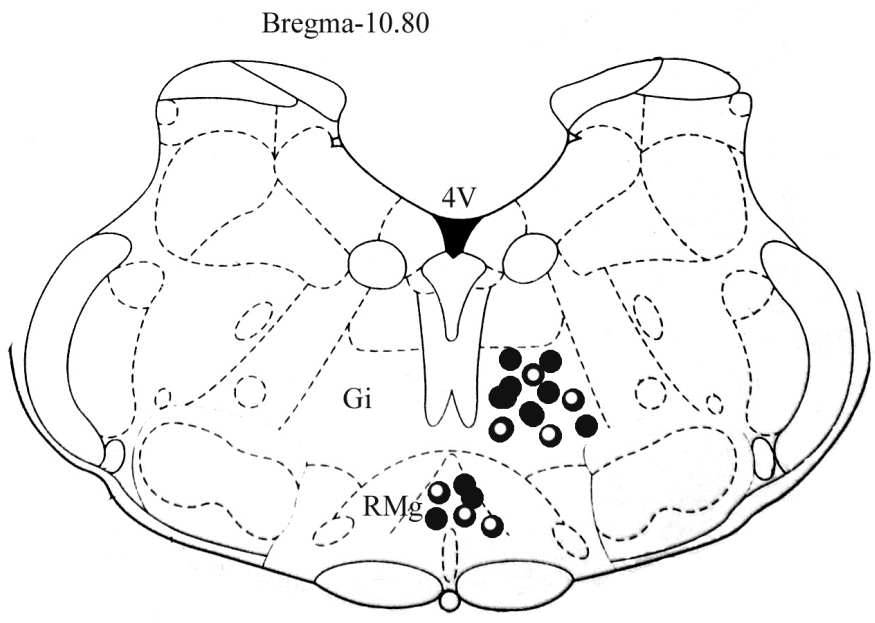

Figure 4: Diagramatic coronal section of the rat Gi and RMG indicating the location of the microiontophoresis electrode tip.

$4 \mathrm{~V}: 4^{\text {th }}$ ventricle; Gi: Gigantocellular reticular nucleus; RMg: Raphe magnus nucleus. Filled circles: Excited; Unfilled circles: Inhibited.

\section{CONCLUSION}

When DLPAG was locally stimulated in a rat, the analgesia characteristic resemble with those of electroacupuncture on ST36 point, and the analgesic effect appear only in the period when VLPAG, RMg and Gi are individually stimulated.The rates of the excited neurons in VLPAG, $\mathrm{RMg}$ and $\mathrm{Gi}$ are increased when microiontophoresis of morphine is performed. This suggests that there are mechanisms inhibiting the painful impulse in input of spinal cord by influence of endogenous morphine-type substance affecting neurons in VLPAG, RMg, and Gi among the mechanisms of electroacupuncture analgesia on ST36 point.

\section{ACKNOWLEDGEMENTS}

We are grateful to Dr. Ri Nam Chol from National Academy of Sciences, DPR of Korea, for his technical assistance in verifying the position of tip of electrode.

\section{CONFLICT OF INTEREST}

The authors declare no conflict of interest.

\section{ABBREVIATIONS}

PAG: Periaqueductal Central Gray; RMG: Raphe Magnus Nucleus; Gi: Gigantocellular Reticular Nucleus; DLPAG: Dorsolateral Periaqueductal Gray; VLPAG: Ventrolateral Periaqueductal Gray; TFL: Tail Flick Latency; MB: Methylene Blue.

\section{REFERENCES}

1. Paxinos G, Watson C. The rat brain in stereotaxic coordinates. Academic Press 1997.

2. Kovács $P$, Dénes $V$, Kellényi $L$, Hernádi I. Microiontophoresis electrode location by neurohistological marking: comparison of four native dyes applied from current balancing electrode channels. J Pharmacol Toxicol Methods. 2005;51(2):147-51. doi: 10.1016/j.vascn.2004.08.002, PMID 15767208.

3. Tortorici $\mathrm{V}$, Morgan MM, Vanegas $\mathrm{H}$. Tolerance to repeated microinjection of morphine into the periaqueductal gray is associated with changes in the behavior of off- and on-cells in the rostral ventromedial medulla of rats. Pain 2001;89(2-3):237-44. doi: 10.1016/s0304-3959(00)00367-5, PMID 11166480.

4. Zhao M, Li Q, Tang JS. The effects of microinjection of morphine into thalamic nucleus submedius on formalin-evoked nociceptive responses of neurons in the rat spinal dorsal horn. Neurosci Lett. 2006;401(1-2):103-7. doi: 10.1016/..neulet.2006.02.075, PMID 16556485

5. William FG. Review of medical physiology. New York: McGraw-Hill; 2005. p. 136-42.

6. Yang ZL, Zhang Y, Wu G. Distinct effect of orphanin FQ in nucleus raphe magnus and nucleus reticularis gigantocellularis on the rat tail flick reflex. Neurosci Lett. 2001;306(1-2):69-72. doi: 10.1016/s0304-3940(01)01874-2, PMID 11403960

7. Basbaum A, Marley N, Keefe O. Effect of spinal cord lesions on the analgesic properties of electrical brain. Brain Res. 2007;177(1):126-33

8. Marx JL. Analgesia: how the body inhibits pain perception. Science. 1977;195(4277):471-3. doi: 10.1126/science.195.4277.471, PMID 17734736

9. Mayer DJ, Price DD, Rafii A. Antagonism of acupuncture analgesia in man by the narcotic antagonist naloxone. Brain Res. 1977;121(2):368-72. doi: 10.1016/0006-8993(77)90161-5, PMID 832169

10. Pomeranz B, Cheng R, Law P. Acupuncture reduces electrophysiological and behavioral responses to noxious stimuli: pituitary is implicated. Exp Neurol. 1977;54(1):172-8. doi: 10.1016/0014-4886(77)90243-6.

11. Repkin AH, Proudfit HK. Primary afferent depolarization as a mechanism of mor phine analgesia. Pharmacologist. 1994;16:141-6.

12. Ross $H$, Tsung-ping S. Opiates and endogenous peptides. Amsterdam, NY 1997. p. $35-40$

13. Simon EJ. Demonstration of stereospecific opiate binding in cultures of feta mouse dorsal root ganglia and spinal cord. Soc Neurose. $7^{\text {th }}$ Ann. Mtg. Galitpp. 1977;301.

14. Takeshge C. Modulation of EEG and unit discharge of deep structure of brain during acupunctural stimulation and hypnosis of rabbit. Adv Pain Res Ther $1976 ; 1: 781-5$

15. Takehige $C$. The relationship between midbrain neurons (periaqueductal centra gray and midbrain reticular formation) and acupuncture analgesia or animal hypnosis. IBRO News. 1978;6(1):28.

16. Takesige C. Individual effectiveness of acupuncture analgesia and endogenous morphine like factors. Neurosci Lett. 1979;13;Suppl 2:431-2. 